\title{
Recognition of the Immunodominant Myelin Basic Protein Peptide by Autoantibodies and HLA-DR2-restricted T Cell Clones from Multiple Sclerosis Patients
}

\author{
Identity of Key Contact Residues in the B-cell and T-cell Epitopes
}

Kai W. Wucherpfennig, ${ }^{\star} \neq$ Ingrid Catz, ${ }^{\S}$ Stefan Hausmann, ${ }^{\star}$ Jack L. Strominger, ${ }^{\star}$ Lawrence Steinman, ${ }^{\|}$and Kenneth G. Warren ${ }^{\S}$

$*$ Dana-Farber Cancer Institute and ${ }^{\ddagger}$ Department of Neurology, Harvard Medical School, Boston, MA 02115; ${ }^{\S}$ Multiple Sclerosis Patient Care and Research Clinic, University of Alberta, Edmonton, Alberta, Canada T6G 2G3; and ${ }^{\|}$Department of Neurology and Neurological Sciences, Beckman Center for Molecular and Genetic Medicine, Stanford, California 94305-5429

\begin{abstract}
Myelin basic protein (MBP) may be an important autoantigen in multiple sclerosis (MS), with the $\mathrm{MBP}(82-100)$ region being immunodominant for $T$ cells and autoantibodies. The structural requirements for autoantibody recognition were compared to those previously defined for MBP-specific T cell clones. MBP autoantibodies were affinity-purified from central nervous system lesions of 11/12 postmortem cases studied. The MBP(83-97) peptide was immunodominant in all 11 cases since it inhibited autoantibody binding to MBP $>95 \%$. Residues contributing to autoantibody binding were located in a 10-amino acid segment (V86-T95) that also contained the MHC/T cell receptor contact residues of the T cell epitope. In the epitope center, the same residues were important for antibody binding and $T$ cell recognition. Based on the antibody-binding motif, microbial peptides were identified that were bound by purified autoantibodies. Autoantibody binding of microbial peptides required sequence identity at four or five contiguous residues in the epitope center. Microbial peptides previously found to activate $T$ cell clones did not have such obvious homology to MBP since sequence identity was not required at MHC contacts. The similar fine specificity of $B$ cells and $T$ cells may be useful for tolerance induction to MBP in MS. (J. Clin. Invest. 1997. 100:1114-1122.) Key words: autoimmunity $\bullet$ antigen recognition $\cdot \mathrm{B}$ cells $\bullet$ viral peptides $\bullet$ bacterial peptides
\end{abstract}

\section{Introduction}

Multiple sclerosis (MS) is a chronic inflammatory disease of the central nervous system $(\mathrm{CNS})^{1}$ myelin. The inflammatory process is characterized by focal infiltration of T cells, B cells, and macrophages, and by a loss of myelin (1). Several lines of

Address correspondence to Kai W. Wucherpfennig, Mayer Building Room 623, Dana-Farber Cancer Institute, 44 Binney Street, Boston, MA 02115. Phone: 617-632-3086; FAX: 617-632-2662; E-mail: wucherpf@mbcrr.harvard.edu

Received for publication 5 February 1997 and accepted in revised form 17 June 1997.

J. Clin. Invest.

(c) The American Society for Clinical Investigation, Inc. 0021-9738/97/09/1114/09 \$2.00

Volume 100, Number 5, September 1997, 1114-1122

http://www.jci.org evidence indicate that myelin basic protein (MBP), an abundant protein component of myelin, is a target antigen for $\mathrm{T}$ cells and autoantibodies in MS. The immunodominant $\mathrm{T}$ cell epitope was localized to residues $82-100$ of MBP; this MBP peptide binds with high affinity to the disease-associated HLADR2 molecule, and is recognized by HLA-DR2-restricted T cell clones from MS patients. The MBP(82-100) peptide contains an epitope for DR2 (DRA, DRB1*1501)-restricted T cells as well as an epitope for T cells restricted by other DR antigens (2-9). The same region of human MBP is also immunodominant for MBP-specific autoantibodies purified from the CNS white matter of MS patients. The epitope for tissuebound autoantibody was localized to residues 82-99 of MBP, while the epitope for free, unbound antibody was localized to residues 75-106 (10-16).

MBP-specific B cells have been immunolocalized in MS lesions, and local synthesis of MBP-specific autoantibodies in the CNS of MS patients has been demonstrated $(17,13)$. Tissue infiltration by MBP-specific T cells and B cells may be important in the autoimmune response against MBP. Antigenspecific B cells are efficient antigen-presenting cells, since they internalize antigen through surface immunoglobulin $(18,19)$. The cognate interaction of antigen-specific B cells and $\mathrm{T}$ cells results in the activation of $\mathrm{CD}^{+} \mathrm{T}$ cells; activated $\mathrm{T}$ cells in turn enhance antibody production by $\mathrm{B}$ cells through cognate interactions (CD40-CD40 ligand) and the secretion of cytokines $(20,21)$. B cell-T cell collaboration may therefore result in the simultaneous expansion of MBP-specific T cells and B cells in MS lesions. MBP-specific autoantibodies may also enhance Fc receptor-mediated phagocytosis and presentation of MBP or myelin by macrophages.

In this paper, the fine specificity of MBP autoantibodies was examined using antibodies that were affinity-purified from postmortem CNS tissue of eleven MS cases. Peptide residues that were critical for autoantibody binding were identified, allowing a detailed comparison to the $\mathrm{T}$ cell epitope that was previously characterized. The antibody recognition motif was used to identify viral and bacterial peptides that were bound by affinity-purified MBP-specific autoantibodies. A peptide from human papillomavirus that was previously found to activate a human MBP-specific T cell clone was bound by autoantibodies from all MS patients studied. These results demonstrate that MBP-specific autoantibodies have a remarkably similar fine specificity for the immunodominant peptide of human myelin basic protein.

1. Abbreviations used in this paper: CNS, central nervous system; MBP, myelin basic protein; MS, multiple sclerosis; TCR, T-cell receptor. 


\section{Methods}

Purification of MBP autoantibodies from postmortem MS brain tissue. Tissue-bound MBP-specific autoantibodies were purified from postmortem CNS tissue by affinity chromatography, as previously described (13). In brief, CNS tissue was cut into thin slices, washed extensively with saline, and then homogenized in $0.01 \mathrm{M}$ PBS, pH 7.2, containing $0.2 \%$ sodium azide, $0.005 \mathrm{M}$ pepstatin and $0.004 \mathrm{M} \epsilon$-aminocaproic acid. The homogenate was centrifuged at 100,000 $\mathrm{g}$ and tissue-bound antibodies were released by resuspending the pellet in $0.1 \mathrm{M}$ glycine- $\mathrm{HCl}, \mathrm{pH} 2.2$, containing $0.05 \mathrm{M} \epsilon$-amino-caproic acid and $0.2 \%$ sodium azide. After a 1 -h incubation, the samples were centrifuged at $100,000 \mathrm{~g}$, and the supernatant was neutralized. IgG was purified from these neutralized supernatants by protein $A$ or protein $G$ affinity chromatography (Protein A or Protein G Sepharose 4 Fast Flow; Pharmacia Diagnostics AB, Uppsala, Sweden). After elution of IgG from the protein A or protein $\mathrm{G}$ column, antibodies were immediately neutralized and dialyzed. Purified IgG migrated as a single band on SDS-PAGE under nonreducing conditions, and as heavy and light chains under reducing conditions. MBP affinity chromatography was used to purify MBP-specific antibodies from the IgG fraction. $\mathrm{MBP}$ was purified from human brain and coupled to $\mathrm{CNBr}$-activated Sepharose 4B beads (Pharmacia Diagnostics AB). Purified IgG was loaded on the MBP affinity column, the column was washed with $0.02 \mathrm{M}$ phosphate buffer, $\mathrm{pH} 7.0$, and MBP-specific antibodies were eluted with $0.1 \mathrm{M}$ glycine- $\mathrm{HCl}, \mathrm{pH}$ 2.2. After elution, purified antibodies were immediately neutralized and concentrated after dialysis. Protein purity was assessed by SDS-PAGE.

Analysis of antibody binding. The specificity of purified MBP autoantibodies was examined in a solid-phase radioimmunoassay; synthetic peptides in the liquid phase were used to compete for the binding of autoantibody to immobilized MBP (13). To allow for comparison of data from different patients, antibody concentration in the assay was normalized to $10 \mu \mathrm{g} / \mathrm{ml}$ of affinity-purified antibody. Immulon microtiter plates were coated with $1 \mu \mathrm{g} /$ well of purified human MBP, and plates were stored at $4^{\circ} \mathrm{C}$. Plates were blocked with $1 \%$ BSA in $0.05 \mathrm{M}$ barbitol, $0.05 \mathrm{M} \mathrm{NaCl}, \mathrm{pH} 7.2$, for $1 \mathrm{~h}$, and were then washed with $0.05 \mathrm{M}$ barbitol, $0.05 \mathrm{M} \mathrm{NaCl}, 0.05 \%$ Tween $20, \mathrm{pH}$ 7.2. For the competition assay, synthetic peptides and purified MBP autoantibodies were mixed at a final concentration of $10 \mu \mathrm{g} / \mathrm{ml}$ of antibody, and of $10 \mu \mathrm{g} / \mathrm{ml}$ of synthetic peptide for $2 \mathrm{~h}$ at room temperature. $100 \mu \mathrm{l}$ (corresponding to $1 \mu \mathrm{g}$ of antibody) were then added to each well of the MBP-coated plates, and incubated at room temperature for $1 \mathrm{~h}$. MBP-bound antibody was detected using an Fc-specific anti-human IgG antibody (ICN Pharmaceuticals, Costa Mesa, CA) $\left(1 \mathrm{~h}\right.$, room temperature), followed by $\left.{ }^{[125} \mathrm{I}\right]$-labeled protein $\mathrm{A}$ (60,000-85,000 cpm/well) (1 h, room temperature). Plates were washed twice with $\mathrm{H}_{2} \mathrm{O}$; dried, individual wells were broken from the strips and placed in a $\gamma$-counter.

Binding of MBP-specific autoantibodies to viral and bacterial peptides. Biotinylated peptides were synthesized on pins in a 96-well format (Chiron Mimotopes, San Diego, CA). Peptides were solubilized in $40 \%$ acetonitrile, $100 \mathrm{mM}$ Hepes, $\mathrm{pH} 7.4$, at a concentration of 2 $\mathrm{mg} / \mathrm{ml}$, and were subjected to matrix-assisted laser desorption mass spectroscopy (Lasermat; Finnigan, San Jose, CA). For the direct binding assay, plates were coated with $1 \mu \mathrm{g} /$ well of streptavidin, and were then blocked with $1 \%$ BSA in $0.05 \mathrm{M}$ barbitol, $0.05 \mathrm{M} \mathrm{NaCl}, \mathrm{pH}$ 7.2 , for $1 \mathrm{~h} .1 \mu \mathrm{g}$ of biotinylated peptide was added to each well in a $100-\mu$ l volume ( $1 \mathrm{~h}$, room temperature), followed by blocking with $1 \%$ BSA in barbitol buffer. After washing, purified MBP-specific autoantibody was added $(100 \mu \mathrm{l}, 10 \mu \mathrm{g} / \mathrm{ml})$ and incubated for $1 \mathrm{~h}$ at room temperature. Bound antibody was detected with anti-human $\mathrm{IgG}$, followed by [ $\left.{ }^{125} \mathrm{I}\right]$-labeled protein $\mathrm{A}$ as described above.

\section{Results}

Definition of $M B P$ peptide residues that are critical for autoantibody binding. MBP-specific autoantibodies were purified from postmortem CNS tissue of 12 MS cases by two-step affinity chromatography. In 10 of the $12 \mathrm{MS}$ cases, the yield of purified autoantibody (after MBP affinity chromatography) was 0.44 $0.71 \mathrm{mg}$ of purified autoantibody from $\sim 2 \mathrm{~g}$ of tissue; in one MS case (patient D) the yield was much higher $(6.01 \mathrm{mg})$. MBP autoantibodies constituted $13.8-18.4 \%$ of the total IgG in 10 of the MS cases, and $46.5 \%$ of the total $\mathrm{IgG}$ in patient D. From one of the samples, no purified MBP autoantibody was obtained. Two different radioimmunoassays were used to examine the specificity of purified autoantibodies. In the first assay, antibody binding to immobilized human MBP was examined (Figs. 1 and 2); in the second assay, biotinylated peptides were captured on streptavidin-coated plates (Table I).

A previous study had demonstrated that tissue-bound, MBP-specific autoantibodies that were purified from the CNS white matter of a MS patient were specific for the MBP(82-99) peptide (16). The MBP(83-97) peptide (ENPVVHFFKNIVTPR) and a panel of alanine analogs of $\operatorname{MBP}(83-97)$ were used to examine the specificity of autoantibodies from the $11 \mathrm{MS}$ cases (Fig. 1, patients A-J, Fig. $2 b$ : patient K). In all patients, the MBP(83-97) peptide inhibited binding of affinity-purified autoantibodies to MBP $>95 \%$, indicating that this epitope was immunodominnant for tissue-bound autoantibodies in all of these patients. Inhibition was specific since substitution of some peptide positions (particularly K91) by alanine (Fig. 1), other L-amino acids or D-amino acids (Fig. 2) greatly reduced the ability of peptides to compete for autoantibody binding to MBP.

Peptide residues that contributed to autoantibody binding were located in a 10-amino acid segment between V86 and T95 (ENPVVHFFKNIVTPR) since alanine substitutions in this segment affected the ability of analog peptides to compete for autoantibody binding to MBP. In all patients, the core of the epitope was located between H88 and I93, with the epitope being centered around residues F89, F90, K91, and N92. In 7 of 11 MS cases (patients A-G), substitution of K91 by alanine abrogated antibody binding (Fig. 1). Substitution of K91 by other L-amino acids or D-lysine (Fig. $2 a$, patient A) confirmed that K91 was a key residue. In four other MS cases (patients $\mathrm{H}-\mathrm{K}$ ) (Fig. 1, Fig. $2 b$ ), analog peptides of K91 showed a moderate degree of binding to MBP (competition of $\sim 20 \%$ ). In these MS patients, peptide positions F89 and F90 represented primary contact residues (Figs. 1-3).

Comparison of the T cell and autoantibody epitopes. The fine specificity of MBP-specific autoantibodies described above was strikingly similar to that previously established for MBPspecific $\mathrm{T}$ cell clones from patients with the disease-associated HLA-DR2 haplotype. These MBP-specific T cell clones recognized a 15-amino acid peptide (MBP 83-97: ENPVVHFFKNIVTPR) bound to different HLA-DR2 subtypes (DRB1*1501 or DRB1*1602) or to HLA-DQ1 (DQA1*0101, DQB1*0501) $(8,22,23)$. Two different numbering systems have been used for this MBP peptide, corresponding to human MBP (residues 83-97) and the cDNA sequence of porcine MBP (residue 85-99) (16, 2). In this work, the former numbering system was used, corresponding to that previously used in studies of autoantibodies.

The same 10-amino acid peptide segment that represented the antibody epitope contained the MHC binding/TCR contact residues of the T cell epitope (Fig. 3). Also, both the antibody and the $\mathrm{T}$ cell epitope were centered on the H88-K91 segment, and F89 and K91 were key contact residues both for MBP-specific T cell clones and autoantibodies. Important dif- 

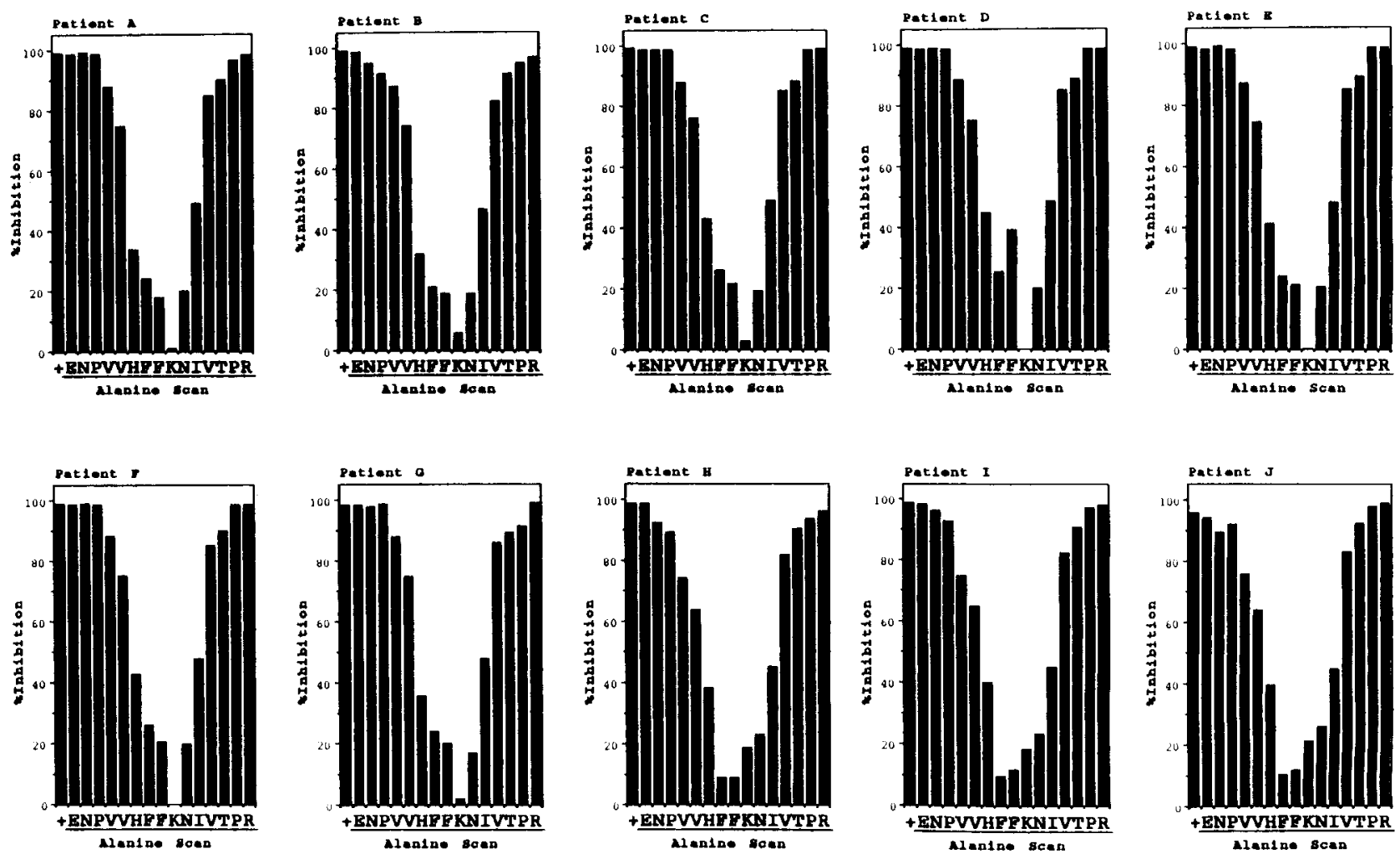

Figure 1. Specificity of MBP-specific autoantibodies purified from MS lesions. MBP-specific autoantibodies were purified from CNS white matter of 11 MS cases (patients A-J shown in Fig. 1, patient K shown in Fig. $2 b$ ) by two-step affinity chromatography. The binding of autoantibodies was examined in a radioimmunoassay in which soluble MBP peptides were used to compete for binding of autoantibodies to immobilized MBP. Bound autoantibody was detected with an anti-human IgG antibody and [ $\left.{ }^{125} \mathrm{I}\right]-$ labeled protein A. The MBP(83-97) peptide (+, positive control) and analog peptides of MBP(83-97) in which individual positions were substituted by alanine (alanine scan) were used as competitors.

In all MS cases examined, the MBP(83-97) peptide inhibited binding of autoantibodies to MBP by $>95 \%$, indicating that this peptide represented the immunodominant segment. The autoantibody epitope was located in a 10-amino acid segment (V86-T95), and was centered around residues $\mathrm{H} 88$, F89, F90, K91, and N92. In seven of the patients (A-G), substitution of K91 by alanine resulted in a complete loss of binding to MBP; in four other MS cases, F89 and F90 were key residues.

ferences between the antibody and the T cell epitope were that a 13-15 amino acid peptide was required for optimal stimulation of MBP-specific T cell clones, while autoantibodies bound a 10-amino acid peptide. Also, peptide residues in the center of the antibody epitope (H88, F89, F90, K91) could not be substituted by structurally related amino acids (Fig. 2). In the $\mathrm{T}$ cell epitope, only $\mathrm{T}$ cell receptor (TCR), but not MHC contact residues, had to be conserved since MHC contact residues (V87 and F90) could be substituted by other hydrophobic amino acids $(8,22,24)$.

Definition of the peptide motif required for autoantibody binding. The requirements for autoantibody binding to MBP were further examined using a panel of 44 analog peptides with single amino acid substitutions in the VVHFFKNI segment (Fig. 2). Analysis of autoantibodies from two patients (A and $\mathrm{K}$ ) demonstrated that the FFK recognition motif in the epitope center had to be fully conserved. Even conservative substitutions of F89 and F90 by other aromatic (Y, W) or by aliphatic residues $(\mathrm{V}, \mathrm{L}, \mathrm{I})$ greatly reduced the ability of synthetic peptides to compete for autoantibody binding to MBP (Fig. 2). Autoantibodies from the two patients had a similar fine specificity to this large panel of analog peptides, with a difference in the relative contribution of K91 to antibody binding.
These results were confirmed using 10-amino acid peptides with D-amino acid substitutions (Fig. 2).

Binding of microbial peptides by affinity-purified, $M B P$ specific autoantibodies. The loss of tolerance in MS may result from a challenge of the immune system by microbial peptides that have sufficient structural similarity with immunodominant $\mathrm{T}$ cell and B cell epitopes (24-26). Clinical studies on cerebrospinal fluid samples from MS patients have provided evidence for the local synthesis of antibodies in the CNS that react with a diverse group of viral and bacterial antigens, but binding of microbial antigens by purified autoantibodies has not been studied $(27,28)$. Microbial peptides that were bound by MBP-specific autoantibodies were identified through a search of the PIR protein database with the HFFK or FFKN motifs, using the program findpatterns of the Genetics Computer Group (Madison, WI) software. A total of 213 sequences from the database met the criteria (145 with the FFKN motif, 68 with the HFFK motif). 23 peptides were synthesized with an $\mathrm{NH}_{2}$-terminal biotin and a four-amino acid spacer (SGSG) between the biotin moiety and the 15-amino acid viral/bacterial peptide sequence (Table I).

Binding of microbial peptides by affinity-purified, MBPspecific autoantibodies was examined in a direct binding assay 


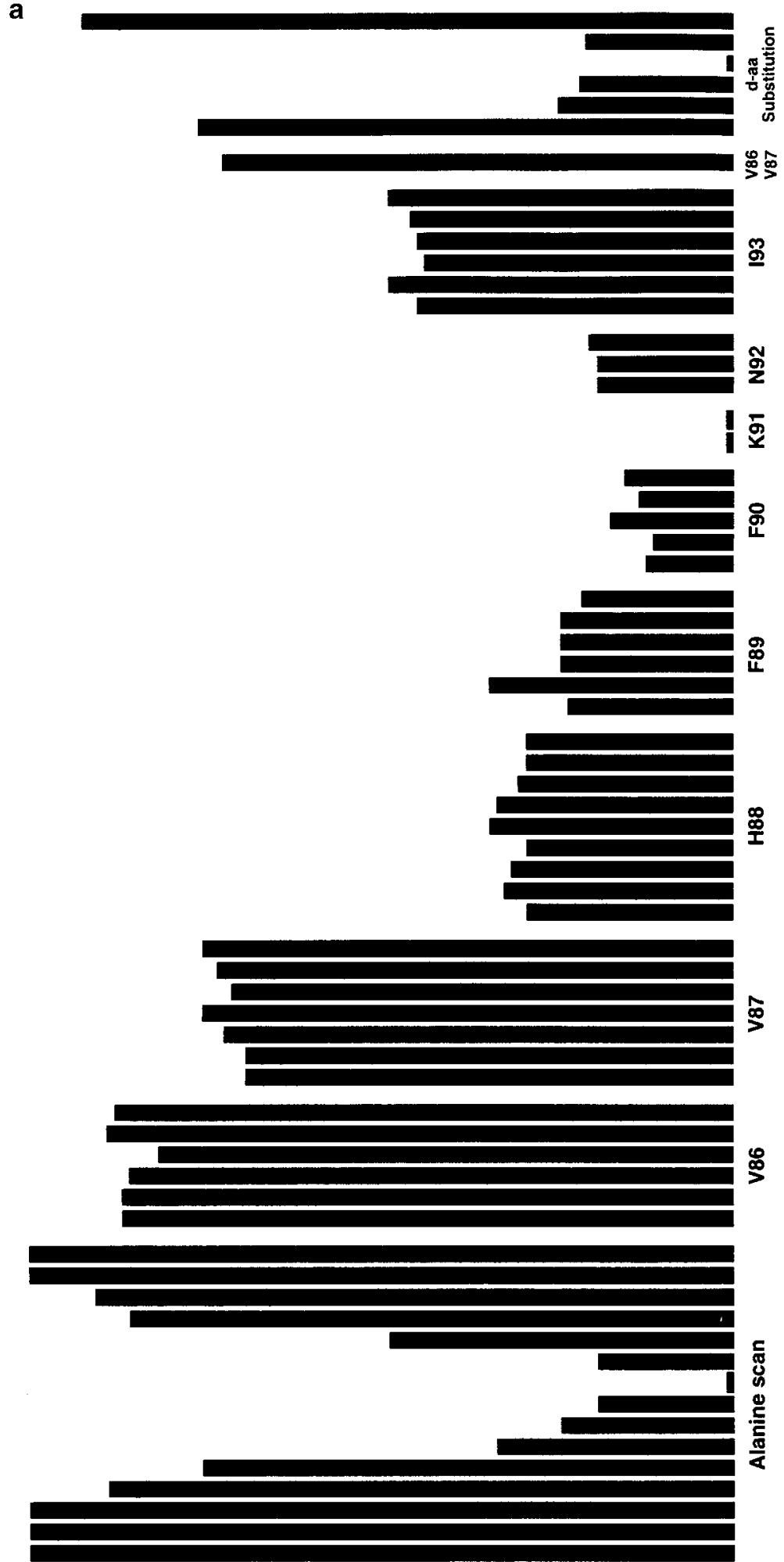

\begin{tabular}{lllllll:l|l|l}
$V$ & $H$ & $F$ & $F$ & $K$ & $N$ & & $V$ & $t$ & $P$ \\
$V$ & $H$ & $F$ & $F$ & $K$ & $\mathbf{n}$ & & $V$ & $T$ & $P$ \\
$V$ & $H$ & $F$ & $F$ & $K$ & $N$ & & $V$ & $T$ & $P$ \\
$V$ & $H$ & $F$ & $f$ & $K$ & $N$ & & $V$ & $T$ & $P$ \\
$V$ & $H$ & $f$ & $F$ & $K$ & $N$ & & $V$ & $T$ & $P$ \\
$V$ & $H$ & $F$ & $F$ & $K$ & $N$ & $V$ & $T$ & $P$
\end{tabular}

离

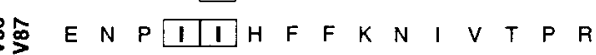

\begin{tabular}{lllllllllll|llll}
$E$ & $N$ & $P$ & $V$ & $V$ & $H$ & $F$ & $F$ & $K$ & $N$ & $F$ & $V$ & $T$ & $P$ & $R$
\end{tabular}

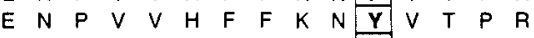

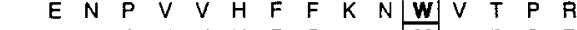

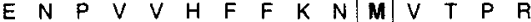

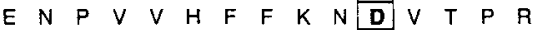
E N P V V V H F F

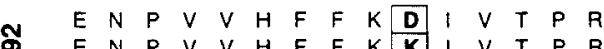

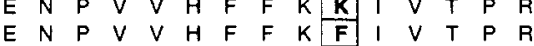

- ENPVVHFF E N P P $V$ V E N P V V

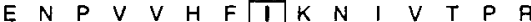
\begin{tabular}{lllllll|l|lllllll}
$E$ & $N$ & $P$ & $V$ & $V$ & $H$ & $F$ & $M$ & $K$ & $N$ & 1 & $V$ & $T$ & $P$ & $R$ \\
$E$ & $N$ & $P$ & $V$ & $V$ & $H$ & $F$ & $D$ & $K$ & $N$ & $\mid$ & $V$ & $T$ & $P$ & $R$
\end{tabular}

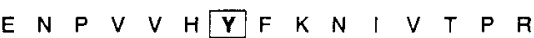
$\begin{array}{lllllllllllllll}E & N & P & V & V & H & \mathbf{W} & F & K & N & \text { I } & V & T & P & R\end{array}$

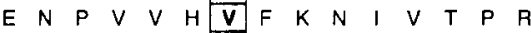
E N P V V V H L

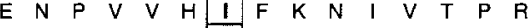

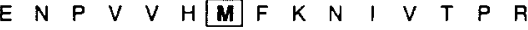

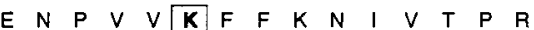
E N N P V V V $\begin{array}{lllllllllllllll}E & N & P & V & V & \mathbf{S} & F & F & K & N & I & V & T & P & R\end{array}$

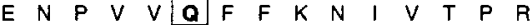

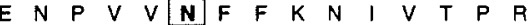
E N N P V V V $\begin{array}{llllllllllllllll}E & N & P & V & V & F & F & F & K & N & I & V & T & P & R\end{array}$ $\begin{array}{lllllllllllllll}E & N & P & V & V & \mathbf{W} & F & F & K & N & I & V & T & P & R\end{array}$ E N $\quad P \quad V \quad V\left[\begin{array}{llllllllll}\hline & F & F & K & N & I & \vee & T & P & R\end{array}\right.$

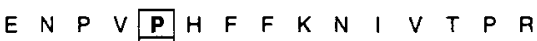

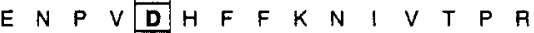

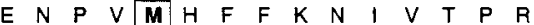

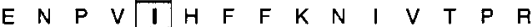

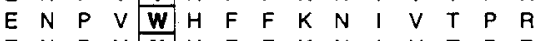

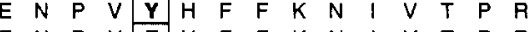

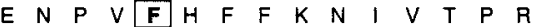

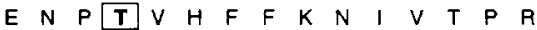
E N P S E N P P

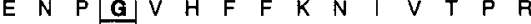
$\begin{array}{lllllllllllllll}E & N & P & F & V & H & F & F & K & N & \text { I } & \vee & T & P & R\end{array}$

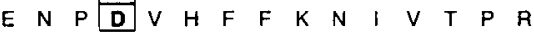

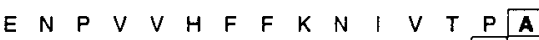

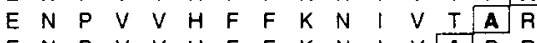

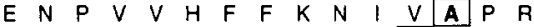

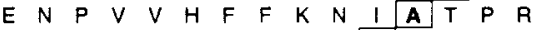

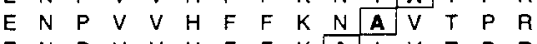

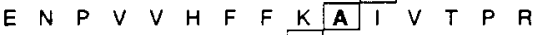
$\begin{array}{lllllllllllllll}E & N & P & V & V & H & F & F & A & N & I & V & T & P & R\end{array}$ E N P V V H F A K N I V T P $A$ E N P V V H $A$\begin{tabular}{llllllll}
\hline & $K$ & $N$ & $V$ & $T$ & $P$ & $B$
\end{tabular} E N N P $P V$ V

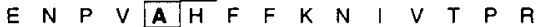

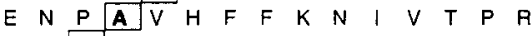
$\begin{array}{lllllllllllllll} & N & A & V & V & H & F & F & K & N & \text { I } & V & T & P & R\end{array}$ $\begin{array}{llllllllllllllll}E & A & P & V & V & H & F & F & K & N & I & V & T & P & R\end{array}$ $A \begin{array}{llllllllllllll}A & P & V & V & H & F & F & K & N & I & V & T & P & R\end{array}$

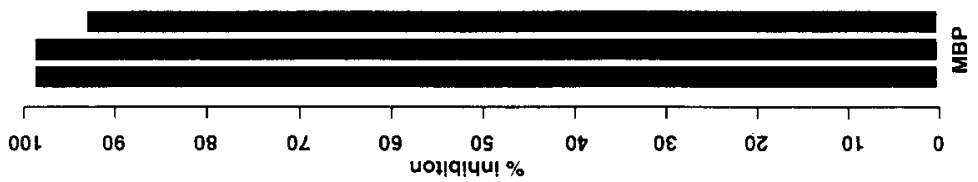

$\begin{array}{llllllllllllllll} & & & V & H & F & F & K & N & 1 & V & T & P & R & T\end{array}$

E N P V V H F F K N

Figure 2 
b
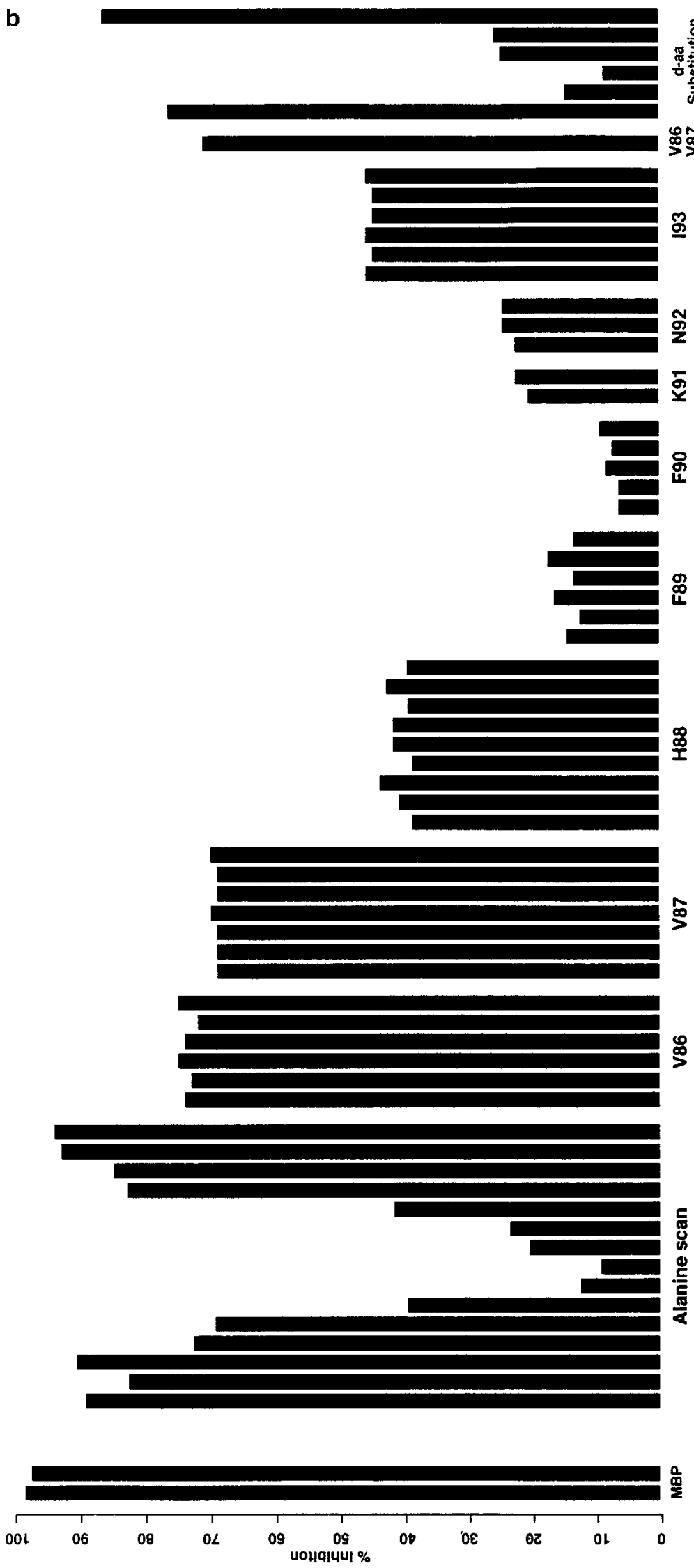

Figure 2 (Continued)
$\begin{array}{llllllllll}V & H & F & F & K & N & 1 & V & \square\end{array}$

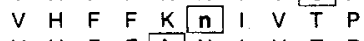

$\begin{array}{lllllllll}V & H & F & F & K & N & N & V & T\end{array}$

$\begin{array}{lllllllll}V & H & F & A & K & N & V & T & P\end{array}$

$\begin{array}{llllllllll}V & H & \text { I } & F & K & N & & V & T & P \\ V & H & F & F & K & N & \text { I } & V & T & P\end{array}$

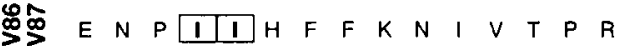

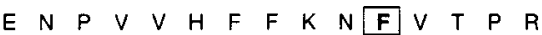

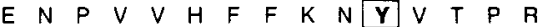

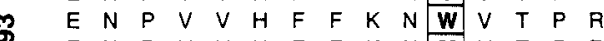

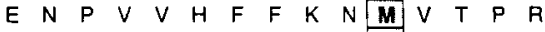

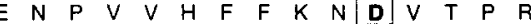

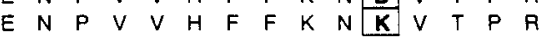

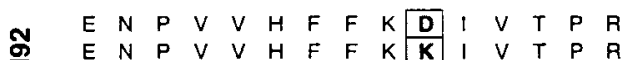

E N P $V$ V V H F F K

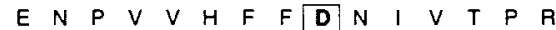

E N $N$ P V V V H

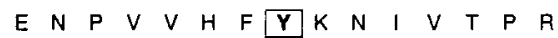

E N $P$ P $V V V$ V

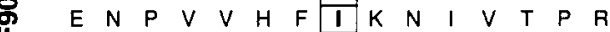

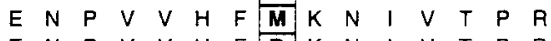

E N P V V H F D K N

E N P V V H $\quad$ Y F K K N I V T P R

E N P V V H W F K N I V T P R

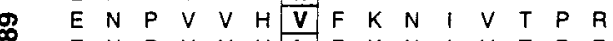

$\begin{array}{lllllllllllllll}E & N & P & V & V & H & L & F & K & N & I & V & T & P & R\end{array}$

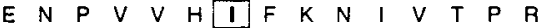

E N P $P V$ V

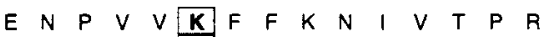

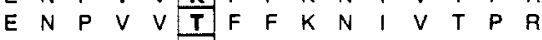

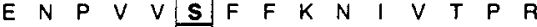

0 E N P V V V O

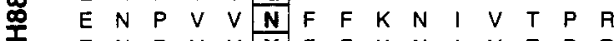

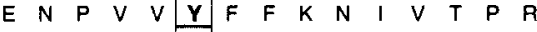

$\begin{array}{lllllllllllllllll}E & N & P & V & V & \mathbf{F} & F & F & K & N & \text { I } & V & T & P & R\end{array}$

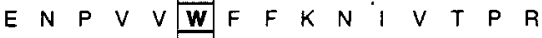

E N P V V D

E N P $P$ P

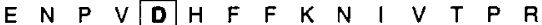

^ E N P V M H F F K N I V T P

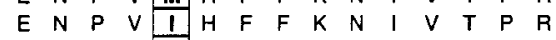

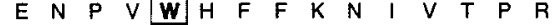

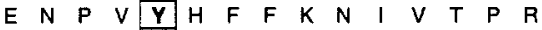

E N P V

E N P T $\quad$ T

E N N P $\begin{array}{lllllllllllll} & \mathbf{S} & V & H & F & F & K & N & \text { I } & V & T & P & R\end{array}$

$\begin{array}{llllllllllllllll}\mathscr{D} & E & N & P & P & V & H & F & F & K & N & I & V & T & P & P\end{array}$

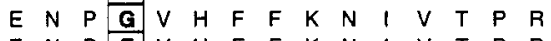

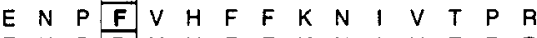

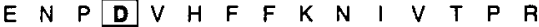

E $N$ N $P$ P $V$ V V

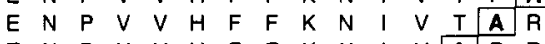

E N P P V V V H F F F K N

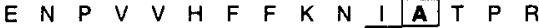

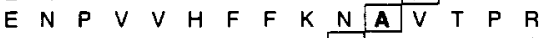

$\begin{array}{lllllllllllllll}E & N & P & V & V & H & F & F & K & A & I & V & T & P & R\end{array}$

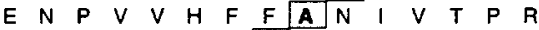

E N P P V V V H

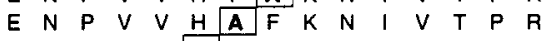

E N P V V V A

$\begin{array}{lllllllllllllll}E & N & P & V & A & H & F & F & K & N & V & V & T & P & R\end{array}$

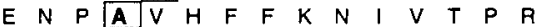

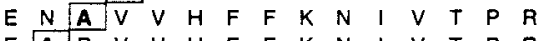

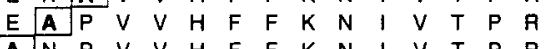

$\begin{array}{lllllllllllllll}A & N & P & V & V & H & F & F & K & N & \text { I } & V & T & P & R\end{array}$

$\begin{array}{llllllllllllllll} & E & N & P & V & V & H & F & F & K & N & \text { I } & V & T & P & A\end{array}$

D E N P V V H F F K N I V T P R T 
in which biotinylated peptides were captured on a streptavidin-coated plate. Antibody binding was detected using an anti-human IgG antibody and $\left[{ }^{125} \mathrm{I}\right]$-labeled protein A or protein G. A peptide derived from the MHC class II-associated invariant chain (CLIP, residues 87-101) was used as a negative control. In the direct binding assay, similar levels of binding were observed with immobilized MBP and with biotinylated MBP peptide captured on streptavidin-coated plates, confirming that the peptide was accessible for autoantibody binding (Table I).

The strongest binding was observed with peptides from the L2 protein of human papillomavirus (type 7 and type 13), which were bound by purified autoantibodies from all $11 \mathrm{MS}$ patients. Autoantibody binding to these papillomavirus peptides was strain-specific since only peptides from type 7 and 13 (which shared the VHFFK-I sequence with the MBP peptide) were bound by autoantibodies from all patients. In contrast, peptides from the L2 protein sequences of strains 40 and 32, in which K91 was substituted by arginine or histidine, were only bound by autoantibodies from patients $\mathrm{H}-\mathrm{K}$ in whom peptide residue K91 was not as important for autoantibody binding as in patients A-G. The human papillomavirus type 7 peptide was previously examined for $\mathrm{T}$ cell recognition, and was found to activate a human MBP-specific T cell clone from an MS patient (24).

The degree of antibody binding to the microbial peptides correlated with the number of amino acids in the epitope center that were identical to the MBP peptide. The peptides from the L2 protein of human papillomavirus (which bound best) were identical at six positions (VHFFK-I) with the MBP peptide, followed by two peptides from Bacillus subtilis and Clostridium cellulare (five-amino acid identity, FFKNI). Twelve peptides with four-amino acid identity (FFKN) showed a similar level of binding in a given patient (Table I).

Autoantibody recognition of microbial peptides required sequence identity over a stretch of four or five amino acids. In contrast, only one of eight peptides (the human papillomavirus L2 protein peptide) that were previously found to activate human MBP-specific T cell clones, had obvious sequence homology with MBP; due to the degenerate MHC binding motif, only TCR contact residues in the center of the epitope had to be conserved (24). This comparison indicated that amino acid identity in the center of the epitope was required for recognition of microbial peptides by autoantibodies, but not by MBPspecific T cell clones (24).

\section{Discussion}

This study demonstrates that MBP-specific autoantibodies have a remarkably similar fine specificity for the immunodominant MBP peptide, as previously described MBP-specific $\mathrm{T}$ cell clones from patients with the MS-associated HLA-DR2 haplotype. The same 10-amino acid sequence represents the autoantibody epitope and the MHC binding/TCR contact residues of the $\mathrm{T}$ cell epitope. Both epitopes are centered on the
Antibody epitope

Pattern I (7 MS cases)

Pattern II (4 MS cases)

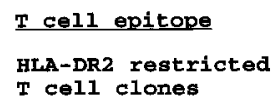

Figure 3. Comparison of the structural requirements for autoantibody binding and $\mathrm{T}$ cell recognition of the immunodominant MBP(83-97) peptide. Residues that contributed to autoantibody binding were located in a 10-amino acid segment (flanked by proline 85 and proline 96). In seven of the MS cases, K91 was a key residue for autoantibody binding; in four cases, F89 and F90 were particularly important. The MHC/TCR contact residues for HLA-DR2

(DRB1*1501 and DRB1*1601) and HLA-DQ1-restricted T cell clones were located in the same 10-amino acid segment that represented the autoantibody epitope. In the T cell epitope H88, F89 and K91 were primary contact residues for MBP-specific TCRs (arrows up); V87 and F90 were MHC anchor residues (arrows down) $(8,22)$. An important difference between the antibody and the T cell epitope was that a 10-amino acid peptide was bound by autoantibodies while a longer peptide (13-15 amino acids) was required for optimal stimulation of MBP specific T cell clones (8).

H88-K91 segment, and F89 and K91 are key contact residues for both autoantibodies and T cell receptors (Fig. 3). An important difference between the autoantibody and the $\mathrm{T}$ cell epitope is that the FFK sequence has to be absolutely conserved for autoantibody binding. In the T cell epitope, the second phenylalanine in the FFK sequence is an MHC anchor residue that can be substituted by other hydrophobic amino acids. Also, the peptide required for optimal T cell stimulation is longer (13-15 amino acids) than that required for autoantibody binding (10 amino acids) (8). The immunodominant $\operatorname{MBP}(82-100)$ region also contains an epitope for $\mathrm{T}$ cells restricted by DR4 and other DR antigens. In this epitope, the primary $\mathrm{MHC}$ anchor residue (F90) is shifted by three amino acids towards the $\mathrm{COOH}$ terminus of MBP (4). The $\mathrm{MHC} /$ TCR contact residues of this epitope have not yet been defined in detail.

The immunodominant autoantibody epitope may be localized on a linear peptide segment of MBP, rather than on a conformation-sensitive epitope, because MBP is flexible due to the presence of many positively charged residues and the absence of disulphide bonds (29). The major difference between the peptide segment that is bound by autoantibodies and the MHC-bound peptide that is recognized by TCRs is that MHC class II binding imposes a particular conformation on the pep-

Figure 2. Fine specificity of MBP autoantibodies. A panel of 44 analog peptides with single amino acid substitutions in the VVHFFKNI sequence was tested for the ability to compete for autoantibody binding to immobilized MBP (patients A and K). In addition, six peptides with D-amino acid substitutions were examined. In both patients, substitution of F89, F90, and K91 (FFK) greatly reduced the ability of these peptides to compete for the binding of autoantibodies to immobilized MBP. For autoantibody binding, these residues had to be absolutely conserved since even conservative substitutions (for example, substitution of F90 and F91 by other aromatic residues or by aliphatic amino acids) greatly diminished autoantibody binding. The contribution of these peptide residues to autoantibody binding was confirmed using analog peptides with single amino acid substitutions by D-amino acids. 
Table I. Binding of Affinity-purified MBP-specific Autoantibodies to Viral and Bacterial Peptides

\begin{tabular}{|c|c|c|c|c|c|c|c|c|c|c|c|c|}
\hline & Sequence & Patient A & Patient B & Patient C & Patient D & Patient E & Patient F & Patient G & Patient $\mathrm{H}$ & Patient I & Patient J & Patient K \\
\hline \multicolumn{13}{|l|}{ Antigen } \\
\hline CLIP peptide(control) & PVSKMRMATPLLMQA & 287 & 217 & 255 & 280 & 257 & 255 & 235 & 240 & 231 & 275 & 263 \\
\hline $\mathrm{MBP}$ & & 29989 & 22469 & 21646 & 33765 & 28463 & 24169 & 21389 & 21296 & 21061 & 27392 & 22755 \\
\hline MBP peptide & ENPVVHFFKNIVTPR & 29187 & 21721 & 20639 & 32405 & 28052 & 23377 & 20769 & 21060 & 19749 & 27244 & 22212 \\
\hline \multicolumn{13}{|l|}{ Viral peptides } \\
\hline Human papillomavirus type 7 & IGGRVHFFKDISPIA & 8061 & 5753 & 5245 & 8184 & 7281 & 5992 & 6096 & 4369 & 5155 & 6823 & 5899 \\
\hline type 13 & IGGRVHFFKDISPIS & 7985 & 5753 & 5661 & 8126 & 7299 & 6115 & 6027 & 4763 & 5237 & 6821 & 6015 \\
\hline type 40 & IGGRVHFFRDISPIG & 745 & 483 & 314 & 345 & 417 & 383 & 360 & 3846 & 3123 & 4279 & 3923 \\
\hline type 32 & IGSRVHFFHDISPIT & 579 & 338 & 287 & 425 & 449 & 342 & 337 & 3365 & 3324 & 4033 & 3740 \\
\hline Epstein-Barr virus & RAHPVYFFKSACPPA & 1987 & 1429 & 1436 & 1937 & 1847 & 1548 & 1421 & 1541 & 1463 & 1801 & 1549 \\
\hline Cytomegalovirus & DRHPVYFFKSACPPN & 1667 & 1278 & 1242 & 1772 & 1665 & 1320 & 1289 & 1358 & 1355 & 1885 & 1403 \\
\hline Dhori virus & SDDFIHFFKAKSYDD & 1631 & 1496 & 1142 & 1823 & 1925 & 1284 & 1264 & 1232 & 1256 & 1571 & 1320 \\
\hline Herpes simplex virus type 1 & GGRRLFFVKAHVRES & 1369 & 979 & 1115 & 1761 & 1973 & 1149 & 1068 & 1139 & 1167 & 1380 & 1067 \\
\hline Epstein-Barr virus & TGGVYHFVKKHVHES & 1386 & 817 & 877 & 1408 & 1589 & 1078 & 959 & 1147 & 1048 & 1543 & 1183 \\
\hline Influenza type A & KDMTKEFFKNKSETW & 3205 & 2446 & 2396 & 3521 & 3487 & 2581 & 2691 & 2820 & 2407 & 3365 & 2723 \\
\hline Epstein-Barr virus & VSGFISFFKNPFGGM & 3066 & 2455 & 2435 & 3574 & 3397 & 2636 & 2854 & 2880 & 2491 & 3351 & 2885 \\
\hline Hepatitis A virus & EVKPASFFKNPHNDM & 3187 & 2448 & 2462 & 3949 & 3374 & 2662 & 2813 & 2881 & 2487 & 3606 & 3298 \\
\hline Human adenovirus & LATYHIFFKNQRIPL & 3218 & 2579 & 2599 & 3897 & 3381 & 2561 & 2722 & 2805 & 2560 & 3499 & 2764 \\
\hline \multicolumn{13}{|l|}{ Bacterial peptides } \\
\hline Streptococcus agalactiae & RNIGYIFFKNSTIDI & 3147 & 2615 & 2408 & 4002 & 3403 & 2806 & 2677 & 2804 & 2401 & 3441 & 2665 \\
\hline Bacillus subtilis & RKVVTDFFKNIPQRI & 4869 & 3637 & 3258 & 4807 & 4703 & 3684 & 3688 & 3637 & 3221 & 4365 & 3737 \\
\hline Bacillus subtilis & KGTIYTFFKNKEELF & 3443 & 2509 & 2361 & 3682 & 3356 & 2654 & 2746 & 2509 & 2550 & 3608 & 2735 \\
\hline Bacillus thuringiensis & PAPADLFFKNADINV & 3549 & 2605 & 2375 & 4170 & 3353 & 2790 & 2849 & 2605 & 2378 & 3403 & 2795 \\
\hline Clostridium cellulare & CDAISNFFKNIGYAN & 4669 & 3581 & 3206 & 4725 & 4873 & 3673 & 3907 & 3581 & 3178 & 4623 & 3725 \\
\hline Vibrio anguillarum & ELLHQRFFKNVESTP & 3489 & 2756 & 2517 & 3521 & 3492 & 2751 & 2743 & 2756 & 2491 & 3693 & 2636 \\
\hline Pseudomonas aeruginosa & LEI IEEFFKNKSGLK & 3605 & 2815 & 2615 & 3662 & 3316 & 2753 & 2739 & 2815 & 2471 & 3534 & 2728 \\
\hline Escherichia coli & LLSAISFFKNTHDF I & 3486 & 2905 & 2392 & 3884 & 3613 & 2745 & 2728 & 2905 & 2400 & 3379 & 2791 \\
\hline Staphylococcus & GIDFDKFFKNRIDTF & 3597 & 2951 & 2386 & 3625 & 3578 & 2743 & 2776 & 2951 & 2607 & 3469 & 2819 \\
\hline Streptococcus equisimilis & RNKIRQFFKNQDKEL & 3500 & 2773 & 2481 & 3743 & 3507 & 2827 & 2869 & 2773 & 2507 & 3467 & 2685 \\
\hline
\end{tabular}

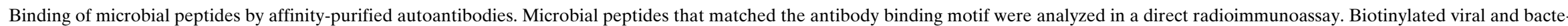

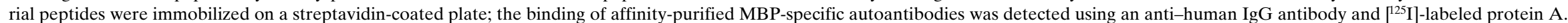

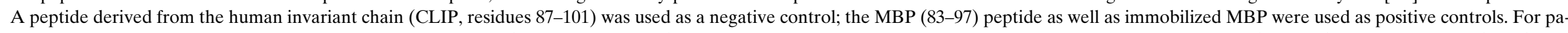

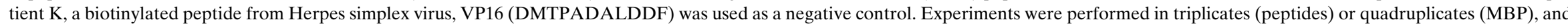
the mean cpm was calculated.

The strongest binding was observed with peptides from the L2 protein of human papillomavirus (type 7 and type 13); antibodies from four patients (H-K) also bound peptides from Papillomavirus

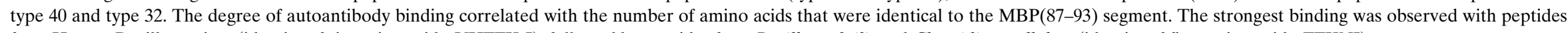
from Human Papillomavirus (identity of six amino acids, VHFFK-I), followed by peptides from Bacillus subtilis and Clostridium cellulare (identity of five amino acids, FFKNI).

Viral peptide sequences were from the following source proteins: 1-4: human papillomavirus L2 protein (type 7, 13, 40 and 32); Epstein-Barr virus BSLF1 protein; cytomegalovirus UL70 protein;

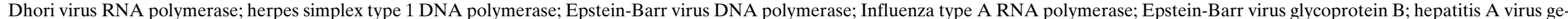

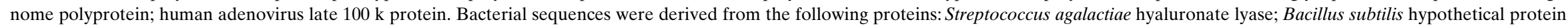

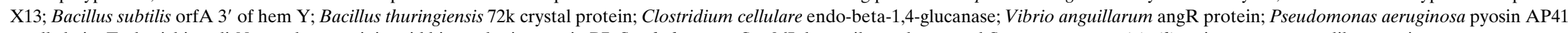
small chain; Escherichia coli $\mathrm{N}$-acetylneuraminic acid biosynthetic protein P7; Staphylococcus Sau96I deoxyribonuclease; and Streptococcus equisimilis stringent response-like protein. 
tide (type II polyproline helix, three residues per turn). Also, a large fraction of the peptide surface is buried in the MHC class II peptide binding site, such that only particular peptide side chains are available for interaction with the TCR $(30,31)$. The fact that peptide side chains that occupy pockets of the MHC class II binding site can be substituted by structurally related amino acids (degenerate MHC-binding motif) accounts for the observation that sequence identity is not required at these peptide positions $(32,24)$. In solution, the MBP peptide may assume a helical conformation, either as an $\alpha$-helix (3.6 residues/ turn) and/or as a 310 -helix (three residues/turn). Nuclear magnetic resonance analysis of short alanine peptides (16 or 17 mers) indicated that peptides in aqueous solution prefer a $3_{10}$-helix; a $3_{10}$-helix may be a stable intermediate between a random coil and an $\alpha$-helical conformation (random coil $\leftrightarrow 3_{10}$ helix $\leftrightarrow \alpha$-helix) (33).

Microbial peptides that activate MBP-specific T cells and B cells may trigger an autoimmune response against MBP; the inflammatory response may be self-perpetuating after an infectious agent has been cleared (or has become latent) since MBP and other myelin proteins are released as the result of myelin destruction $(25,26)$. Microbial peptides that are bound by affinity-purified MBP-specific autoantibodies were identified based on the antibody-binding motif; among these peptides, the strongest autoantibody binding was observed with a peptide from the human papillomavirus L2 protein, a minor capsid protein. Binding of the autoantibody to the native viral protein was not examined because human papillomavirus cannot be propagated in vitro (neither in primary cultures nor in established epithelial cell lines) (34). The peptide segment, however, may be solvent-exposed because two charged residues (lysine and aspartic acid) are located in the center of the epitope.

The colocalization of the immunodominant $\mathrm{T}$ cell and $\mathrm{B}$ cell epitopes of MBP may be important in the autoimmune response against MBP in MS. Antigen-specific B cells are efficient antigen-presenting cells due to specific uptake of antigen via surface immunoglobulin $(18,19)$. Antibody binding to antigen was also shown to modulate antigen processing in human B lymphoblastoid cells. A single bound antibody or its $F(a b)$ fragment could simultaneously enhance the presentation of one $\mathrm{T}$ cell determinant of tetanus toxoid while strongly suppressing the presentation of a different $\mathrm{T}$ cell determinant. Both the suppressed and boosted determinants fell within an extended domain of antigen stabilized (or footprinted) by the antibody during proteolysis (35). Binding by MBP-specific autoantibodies may protect the immunodominant $\mathrm{T}$ cell epitope from proteolytic degradation. MBP is very sensitive to proteolytic degradation, and a brain cathepsin D cleavage site is located in the center of the immunodominant epitope (between F89 and F90 in the FFK motif) (36).

Since studies in the EAE model have demonstrated that systemic administration of soluble MBP peptides induces tolerance and reverses clinical disease $(37,38)$, the immunodominant MBP peptide may be useful for the induction of both T cell and B cell tolerance to MBP in MS.

\section{Acknowledgments}

This research was supported by a grant from the National Multiple Sclerosis Society (USA), a grant from the Alberta Heritage Foundation for Medical Research, the Lorna and M.G. (Bud) Atkin Endow- ment Fund for Multiple Sclerosis Research at the University of Alberta, the Friends of Northern Alberta Multiple Sclerosis Patient Care and Research Clinic, the Fort Assiniboine Equine Endeavor for Multiple Sclerosis Research, and the National Institutes of Health (CA47554 and NO1.AI.45198). K.W. Wucherpfennig is a Harry Weaver Neuroscience Scholar of the National Multiple Sclerosis Society. S. Hausmann is a postdoctoral fellow of the DAAD (Deutscher Akademischer Austauschdienst).

\section{References}

1. Steinman, L. 1996. Multiple sclerosis: a coordinated immunological attack against myelin in the central nervous system. Cell. 85:299-302.

2. Pette, M., K. Fujita, D. Wilkinson, D.M. Altmann, J. Trowsdale, G. Giegerich, A. Hinkkanen, J.T. Epplen, L. Kappos, and H. Wekerle. 1990. Myelin autoreactivity in multiple sclerosis: recognition of myelin basic protein in the context of HLA-DR2 products by T lymphocytes of multiple sclerosis patients and healthy donors. Proc. Natl. Acad. Sci. USA. 87:7968-7972.

3. Ota, K., M. Matsui, E.L. Milford, G.A. Mackin, H.L. Weiner, and D.A. Hafler. 1990. T-cell recognition of an immunodominant myelin basic protein epitope in multiple sclerosis. Nature (Lond.). 346:183-187.

4. Martin, R., D. Jaraquemada, M. Flerlage, J. Richert, J. Whitaker, E.O. Long, D.E. McFarlin, and H.F. McFarland. 1990. Fine specificity and HLA restriction of myelin basic protein-specific cytotoxic $\mathrm{T}$ cell lines from multiple sclerosis patients and healthy individuals. J. Immunol. 145:540-548.

5. Wucherpfennig, K.W., K. Ota, N. Endo, J.G. Seidman, A. Rosenzweig, H.L. Weiner, and D.A. Hafler. 1990. Shared human T cell receptor V $\beta$ usage to immunodominant regions of myelin basic protein. Science (Wash. DC). 248: 1016-1019.

6. Wucherpfennig, K.W., H.L. Weiner, and D.A. Hafler. 1991. T-cell recognition of myelin basic protein. Immunol. Today. 12:277-282.

7. Valli, A., A. Sette, L. Kappos, C. Oseroff, J. Sidney, G. Miescher, M. Hochberger, E.D. Albert, and L. Adorini. 1993. Binding of myelin basic protein peptides to human histocompatibility leukocyte antigen class II molecules and their recognition by $\mathrm{T}$ cells from multiple sclerosis patients. J. Clin. Invest. 91: $616-628$.

8. Wucherpfennig, K.W., A. Sette, S. Southwood, C. Oseroff, M. Matsui, J.L. Strominger, and D.A. Hafler. 1994. Structural requirements for binding of an immunodominant myelin basic protein peptide to DR2 isotypes and for its recognition by human T cell clones. J. Exp. Med. 179:279-290.

9. Vogt, A.B., H. Kropshofer, H. Kalbacher, M. Kalbus, H.-G. Rammensee, J. Coligan, and R. Martin. 1994. Ligand motifs of HLA-DRB5*0101 and DRB1*1501 molecules delineated from self-peptides. J. Immunol. 151:16651673.

10. Warren, K.G., and I. Catz. 1986. Diagnostic value of cerebrospinal fluid anti-myelin basic protein in patients with multiple sclerosis. Ann. Neurol. 20:20 25 .

11. Warren, K.G., and I. Catz. 1992. Synthetic peptide specificity of antimyelin basic protein from multiple sclerosis cerebrospinal fluid. J. Neuroimmunol. 39:81-90.

12. Warren, K.G., and I. Catz. 1993. Autoantibodies to myelin basic protein within multiple sclerosis central nervous system tissue. J. Neurol. Sci. 115:169176.

13. Warren, K.G., and I. Catz. 1993. Increased synthetic peptide specificity of tissue-CSF bound anti-MBP in multiple sclerosis. J. Neuroimmunol. 43:8796.

14. Warren, K.G., and I. Catz. 1994. Relative frequency of autoantibodies to myelin basic protein and proteolipid protein in optic neuritis and multiple sclerosis cerebrospinal fluid. J. Neurol. Sci. 121:66-73.

15. Warren, K.G., I. Catz, E. Johnson, and B. Mielke. 1994. Anti-myelin basic protein and anti-proteolipid protein specific forms of multiple sclerosis. Ann. Neurol. 35:280-289.

16. Warren, K.G., I. Catz, and L. Steinman. 1995. Fine specificity of the antibody response to myelin basic protein in the central nervous system in multiple sclerosis: the minimal B-cell epitope and a model of its features. Proc. Natl. Acad. Sci. USA. 92:11061-11065.

17. Gerritse, K., C. Deen, M. Fasbender, R. Ravid, W. Boersma, and E. Claassen. 1994. The involvement of specific anti myelin basic protein antibodyforming cells in multiple sclerosis immunopathology. J. Neuroimmunol. 49:153159.

18. Lanzavecchia, A. 1985. Antigen-specific interaction between T and B cells. Nature (Lond.). 314:537-539.

19. Lanzavecchia, A. 1990. Receptor-mediated antigen uptake and its effect on antigen presentation to class II-restricted T lymphocytes. Annu. Rev. Immunol. 8:773-793.

20. Nonoyama, S., D. Hollenbaugh, A. Aruffo, J.A. Ledbetter, and H.D. Ochs. 1993. B cell activation via CD40 is required for specific antibody production by antigen-stimulated human B cells. J. Exp. Med. 178:1097-1102.

21. Paul, W.E., and R.A. Seder. 1994. Lymphocyte responses and cytokines. 
Cell. 76:241-251.

22. Wucherpfennig, K.W., D.A. Hafler, and J.L. Strominger. 1995. Structure of human $\mathrm{T}$ cell receptors specific for an immunodominant myelin basic protein peptide: positioning of T cell receptors on HLA-DR2/peptide complexes. Proc. Natl. Acad. Sci. USA. 92:8896-8890.

23. Wucherpfennig, K.W., J. Zhang, C. Witek, M. Matsui, Y. Modabber, K. Ota, and D.A. Hafler. 1994. Clonal expansion and persistence of human T cells specific for an immunodominant myelin basic protein peptide. J. Immunol. 150: 5581-5592.

24. Wucherpfennig, K.W., and J.L. Strominger. 1995. Molecular mimicry in $\mathrm{T}$ cell mediated autoimmunity: viral peptides activate human $\mathrm{T}$ cell clones specific for myelin basic protein. Cell. 80:695-705.

25. Oldstone, M.B.A. 1990. Molecular mimicry and autoimmune disease. Cell. 50:819-820.

26. Fujinami, R.S., and M.B.A. Oldstone. 1985. Amino acid homology between the encephalitogenic site of myelin basic protein and virus: a mechanism for autoimmunity. Science (Wash. DC). 230:1043-1045.

27. Forghani, B., N.E. Cremer, K.P. Johnson, A.H. Ginsberg, and W.H. Likosky. 1978. Viral antibodies in cerebrospinal fluid of multiple sclerosis and control patients: comparison between radioimmunoassay and conventional techniques. J. Clin. Microbiol. 7:63-69.

28. Vartdal, F., B. Vandvik, and E. Norrby. 1980. Viral and bacterial antibody responses in multiple sclerosis. Ann. Neurol. 8:248-255.

29. Kamholz, J., F. de Ferra, C. Puckett, and R. Lazzarini. 1986. Identification of three forms of human myelin basic protein by cDNA cloning. Proc. Natl. Acad. Sci. USA. 83:4962-4966.

30. Stern, L.J., J.H. Brown, T.S. Jardetzky, R. Urban, J.L. Strominger, and D.C. Wiley. 1994. Crystal structure of the human class II MHC protein HLA-
DR1 complexed with an influenza virus peptide. Nature (Lond.). 368:215-221.

31. Jardetzky, T.S., J.H. Brown, J.C. Gorga, L.J. Stern, R.G. Urban, J.L. Strominger, and D.C. Wiley. 1996. Crystallographic analysis of endogenous peptides associated with HLA-DR1 suggests a common, polyproline II-like conformation for bound peptides. Proc. Natl. Acad. Sci. USA. 93:734-738.

32. Rammensee, H.-G., T. Friede, and S. Stevanovic. 1995. MHC ligands and peptide motifs: first listing. Immunogenetics. 41:178-228.

33. Miick, S.M., G.V. Martinez, W.R. Fiori, P. Todd, and G.L. Millhauser. 1992. Short alanine-based peptides may form 3(10)-helices and not $\alpha$-helices in aqueous solution. Nature (Lond.). 359:653-655.

34. McCance, D.J. 1995. Papillomaviruses. Principles and Practice of Clinical Virology. A.J. Zuckerman, J.E. Banatvala, and J.R. Pattison, editors. John Wiley \& Sons Ltd., New York. 621-633.

35. Simitsek, P.D., D.G. Campbell, A. Lanzavecchia, N. Fairweather, and C. Watts. 1995. Modulation of antigen processing by bound antibodies can boost or suppress class II major histocompatibility complex presentation of different T cell determinants. J. Exp. Med. 181:1957-1963.

36. Whitaker, J.N., and J.M. Seyer. 1979. The sequential limited degradation of bovine myelin basic protein by bovine brain cathepsin D. J. Biol. Chem. 254:6956-6963.

37. Gaur, A., B. Wiers, A. Liu, J. Rothbard, and C.G. Fathman. 1992. Amelioration of autoimmune encephalomyelitis by myelin basic protein synthetic peptide-induced anergy. Science (Wash. DC). 258:1491-1494.

38. Brocke, S., K. Gijbels, M. Allegretta, I. Ferber, C. Piercy, T. Blankenstein, R. Martin, U. Utz, N. Karin, D. Mitchell, et al. 1996. Treatment of experimental encephalomyelitis with a peptide analogue of myelin basic protein. $\mathrm{Na}$ ture (Lond.). 379:343-346. 